\title{
17-alpha hydroxyprogesterone caproate for preterm birth prevention: Where have we been, how did we get here, and where are we going?
}

\author{
Tracy A. Manuck, MD, MSC \\ Division of Maternal-Fetal Medicine, Department of Obstetrics and Gynecology, University of North Carolina School of \\ Medicine, 3010 Old Clinic Building, CB\#7516, Chapel Hill, NC 27599-7516
}

\author{
A R T I C L E I N F O \\ Keywords: \\ Recurrent preterm birth \\ 17-alpha hydroxyprogesterone \\ caproate \\ Perinatal epidemiology \\ Spontaneous preterm labor
}

\begin{abstract}
A B S T R A C T
Prematurity is a major public health problem in the United States and worldwide. Women with a history of a previous preterm birth are at high risk for recurrence. Progesterone is a key hormone involved in pregnancy maintenance. In general, progesterone is thought to maintain pregnancy through several closely linked mechanisms: (1) promotion of uterine quiescence, (2) inhibition of pro-inflammatory cells, and (3) immunosuppressive action. 17Alpha hydroxyprogesterone caproate is currently the only medication approved to prevent recurrent preterm birth. The purpose of this review is to discuss the history of 17-alpha hydroxyprogesterone caproate use for recurrent preterm birth prevention, the rationale behind 17-alpha hydroxyprogesterone caproate administration, and current evidencebased indications for 17-alpha hydroxyprogesterone caproate use.
\end{abstract}

\section{Introduction}

Preterm delivery (birth prior to 37 weeks' gestation) complicates approximately 1 in 10 pregnancies in the United States, is the leading cause of morbidity and mortality among non-anomalous singleton neonates, and remains a major public health problem worldwide. ${ }^{1-6}$ Survivors remain at increased risk for life-long complications, including reduced school performance, behavioral and cognitive difficulties, and medical problems affecting nearly all major organ systems. ${ }^{7-9}$ Over the last several decades, though significant advances have been made in the care of the preterm neonate, resulting in lowering the threshold of viability to 22 weeks' gestation in some tertiary care centers, similar advances have not been made in obstetrics, and preterm birth remains difficult to predict, prevent, and treat.

The physiologic processes that occur to initiate term and preterm labor are complex, multifactorial, and incompletely understood. Normal pregnancy maintenance depends on maintaining uterine quiescence despite both internal and external stimuli. External stimuli that may lead to aberrations in the maintenance of pregnancy and thus, preterm delivery, include factors such as infection (bacterial and viral), decidual hemorrhage, uterine stretch due to overdistention, and maternal or fetal stress. ${ }^{10,11}$ The contribution of the fetus and the placenta are also important but often overlooked; the unique fetal genome and physiologically active placental tissue with the ability to synthesize steroid hormones may play a pivotal role in the pathogenesis of preterm birth in some pregnancies. Finally, hormonal abnormalities may contribute to adverse pregnancy outcomes and variation in the timing of parturition. ${ }^{10,11}$

Supplementation with progesterone during pregnancy is currently the only effective option for the prevention of spontaneous preterm birth in certain high-risk subgroups. Unfortunately, even progesterone supplementation is 
imperfect, and the mechanisms of action remain poorly understood. Paramount to determining the success of progesterone supplementation during pregnancy is identifying women who will benefit. Regrettably, progesterone is not a panacea and it is not efficacious for all women and for all preterm birth indications. Therefore, it is not unexpected that some recent studies of progesterone in pregnancy have reported negative findings.

The purpose of this review is to discuss the history of progesterone use for preterm birth prevention in the United States, and to provide a basis for understanding why this therapy has been widely studied yet has been met with disparate results. We will discuss possible mechanisms of action of progesterone in general and describe current evidence-based indications for progesterone for the prevention of spontaneous preterm birth, focusing on 17-alpha hydroxyprogesterone caproate (17-OHPC, trade name Makena, AMAG Pharmaceuticals, Inc.), currently the only medication approved by the Food and Drug Administration (FDA) for the purposes of prematurity prevention.

\section{History of use of 17-OHPC for preterm birth prevention}

Though 17-OHPC was initially approved by the FDA in 1956 (under the trade name Delalutin) for the treatment of menstrual disorders, uterine cancer, and miscarriage, the first reports of progesterone supplementation for preterm birth prevention were published in the 1960s. One of the first reports included 99 women at high risk for preterm birth from Paris, France; study participants received either intramuscular progesterone three times per week or placebo between 28 and 32 weeks' gestation, and those receiving progesterone had a reduced risk of preterm birth $(\mathrm{OR}=0.24$, 95\% CI: 0.07-0.82). ${ }^{12}$ Unfortunately, inconsistent results, poor study design including heterogeneous inclusion criteria, and theoretical concerns regarding safety limited clinical application of progesterone in the 1960s and 1980s during pregnancy.

In 1990, a meta-analysis of progesterone use in pregnancy was published by Keirse et al., concluding that while there was no support for the role of progesterone in prevention of miscarriage, it may be effective as a prophylactic agent for preterm birth (pooled OR $=0.50,95 \%$ CI: $0.30-0.85) .{ }^{12}$ This new enthusiasm for the use of progesterone for preterm birth prevention prompted several trials that were eventually conducted and reported in the early 2000s. Most notably, in a large multi-center randomized controlled trial (RCT) conducted by the NICHD Maternal-Fetal Medicine Units Network, Meis et al randomized 463 women with a history of a prior spontaneous preterm birth to $250 \mathrm{mg}$ weekly intramuscular injections of 17-OHPC vs. placebo. The rate of recurrent spontaneous preterm birth $<37$ weeks' gestation was reduced from $55 \%$ in the placebo group to $36 \%$ in the $17-$ OHPC group ( $R R=0.66,95 \% \mathrm{CI}: 0.54-0.81) .{ }^{13}$ It was primarily due to the results of this landmark trial that have led to current day (2017) recommendations for 17-OHPC use in clinical practice.

\section{Rationale for studying progesterone}

Progesterone is a key hormone involved in pregnancy maintenance. In early pregnancy, the presence of progesterone is crucial to the survival of the developing embryo. It is produced by the corpus luteum, and if disrupted, or if an anti-progestin is administered, the pregnancy is lost. ${ }^{14}$ By approximately 10 weeks' gestation, primary production of progesterone is assumed by the developing placenta, but the role of progesterone later in pregnancy is less clearly defined. ${ }^{15}$ Administration of progesterone antagonists to women at term will induce cervical ripening and labor; in mouse models, administration of progesterone antagonists during the preterm time period results in premature delivery. ${ }^{16}$ In sheep, goats, and mice, an absolute decrease in progesterone levels and an increase in estrogen precede the onset of labor. In contrast, a relative withdrawal of progesterone at the level of the receptor is thought to precede the initiation of labor in humans. ${ }^{16}$ Though there is consensus that an absolute or relative withdrawal of progesterone is necessary in most mammals for the initiation of both normal and abnormal labor, the mechanisms by which this occurs are incompletely understood. ${ }^{17}$ In general, progesterone is thought to maintain pregnancy through several closely linked mechanisms: (1) promotion of uterine quiescence, (2) inhibition of pro-inflammatory cells, and (3) immunosuppressive action.

\section{Mechanisms of action}

Progesterone exerts its action through several different isoforms of the intracellular progesterone receptor, a member of the steroid-receptor superfamily of nuclear receptors. Progesterone Receptor B (PR-B) is the predominant form of the receptor found during pregnancy in humans. Binding of progesterone to $\mathrm{PR}-\mathrm{B}$ induces a conformational change in the receptor, promoting the transcription of genes that promote uterine relaxation. In contrast, Progesterone Receptor A (PR-A) is a truncated form of the progesterone receptor, and lacks the $164 \mathrm{~N}$-terminal residues. PR-A acts as a repressor of $P R-B$ function. An increase in the ratio of PR-A to PR-B is associated with the onset of labor in humans, creating a functional progesterone withdrawal at the level of the receptor. ${ }^{18,19}$

Progesterone is also theorized to have anti-inflammatory activity. Some of these actions are mediated through the inhibition of monocyte chemoattractant protein-1 (MCP-1), a chemokine that increases in maternal serum during preterm and term labor. ${ }^{20} \mathrm{MCP}-1$ stimulates recruitment of monocytes to the myometrium. Monocytes serve as precursors to tissue macrophages, a key element to the inflammatory cascade. ${ }^{20}$ Immunosuppressive effects of progesterone have been demonstrated in multiple in vitro studies. Inflammation is a common underlying etiology of preterm birth, and is most objectively defined histologically, occurring due to the infiltration of tissues by neutrophils, macrophages, and lymphocytes. ${ }^{21}$

In one study, stimulation of placental cotyledons with an infectious agent (Escherichia coli) resulted in an increase in 
inflammatory cytokines, including TNF-alpha, IL-1 $\beta$, IL-6, and IL-10. When placentas were pre-treated with progesterone (4-pregnene-3, 20-dione), significant blunting in the secretion of these pro-inflammatory cytokines was appreciated. ${ }^{22}$

Results from specific in vitro evaluation of 17-OHPC with regards to mechanisms of action have been less consistent. In one study, pregnant mice were pre-treated with either vaginal progesterone or 17-OHPC before exposure to lipopolysaccharide to induce inflammation-mediated preterm birth. Researchers found that vaginal progesterone, but not 17OHPC, had significant anti-inflammatory effects at the level of the cervix, as it increased the proportion of decidual CD5+ regulatory T-cells, decreased the proportion of CD8+ CD25+ Foxp3+ T-cells and macrophages, and reduced the proportion of myometrial interferon-gamma neutrophils and MMP-9 positive neutrophils and monocytes. ${ }^{23}$ In another murine study focusing on expression of uterine contraction-associated proteins (connexin-43, oxytocin receptor, and cyclooxygenase-2) and miRNA, 17-OHPC did not alter levels of the studied contractile proteins or alter pathways involved with cervical remodeling. ${ }^{24}$ In contrast, Elovitz and colleagues evaluated the effect of pretreating mice with various both medroxyprogesterone acetate and 17-OHPC prior to exposing them to intrauterine lipopolysaccharide; though medroxyprogesterone acetate was more effective, both formulations resulted in the prevention of preterm birth and resulted in the delivery of live pups at term. ${ }^{25}$

\section{General properties and pharmcokinetic characteristics of 17-OHPC}

17-OHPC differs from naturally occurring 17-alpha hydroxyprogesterone by addition of a caproate group, which serves to prolong its half-life. 17-OHPC is synthesized by the acetylation of 17-alpha hydroxyprogesterone with caproic acid in the presence of toluene sulfonic acid. ${ }^{26}$ It is lipophilic and highly protein bound, and is highly stable in the presence of strong acid, high temperatures, and light. ${ }^{27}$ The most common dose is $250 \mathrm{mg}$, administered by intramuscular injection every 7 days. However, this dosing regimen is empiric, and wide variation in 17-OHPC concentrations is observed between individuals in pharmacokinetic studies. ${ }^{28,29}$

17-OHPC is metabolized by human hepatocytes and liver microsomes by the highly polymorphic cytochrome $\mathrm{P} 450$ (CYP) enzyme system, primarily by CYP3A5. Considerable inter-individual variability in the CYP3A5 gene has been reported, which may result in variation in the catalytic activity of the enzyme by as much as 90 -fold. ${ }^{30}$ After administration, peak concentrations are reached in 1-2 days, and the half-life of 17-OHPC is 10-16 days. ${ }^{28,29}$ This half-life is variable between individuals, with notable differences seen with variance in maternal body mass index and race, and is shorter in twin gestations. ${ }^{28,29,31}$ In general, non-Hispanic black women have higher clearance and therefore lower concentrations of 17-OHPC compared to non-Hispanic white women. These differences by race and ethnicity are theorized to be at least partly attributable to known genetic differences in the CYP3A enzyme system, as the CYP3A5 is the predominant CYP3A enzyme in $50 \%$ of non-Hispanic black women but only $30 \%$ of non-Hispanic white women. ${ }^{32}$ 17-OHPC crosses the placenta and has been detected in cord blood plasma as long as 44 days after the last maternal injection. ${ }^{29}$

Because the volume of progesterone produced by the placenta is large, supplementation with additional natural or synthetic progesterone would not be expected to raise the overall serum levels of progesterone significantly. Some critics, therefore, doubt the ability of additional supplementation to locally impact the myometrium or affect clinical outcomes. However, unlike other species where a sudden change in gene signaling occurs at term, human pregnancy is characterized by a more gradual change in progesterone gene signaling, contributing to the functional progesterone withdrawal as described above.

The relationship between 17-OHPC level and clinical outcomes has been evaluated in an attempt to explain part of the variation in clinical outcomes that is observed among women on 17-OHPC. Caritis et al. evaluated the plasma concentrations of 17-OHPC of 315 women receiving 17-OHPC for recurrent preterm birth prevention to determine the relationship between 17-OHPC concentration and clinical efficacy. Blood samples were obtained at a median 27 weeks' gestation after a median of 9 injections. Women with the lowest quartiles of 17-OHPC concentrations $(<8.2 \mathrm{ng} / \mathrm{mL})$ were significantly more likely to experience recurrent preterm birth (46.3\% for lowest quartile vs. $29.2 \%$ for women in other 3 quartiles). ${ }^{33}$ These findings are in contrast to a large prospective observational cohort of primarily Hispanic women where maternal 17-OHPC plasma levels were obtained at 24 and 32 weeks; and there were no observed differences in median 17-OHPC levels were observed when women who delivered $\leq 35$ weeks' gestation were compared with those who delivered $>35$ weeks' gestation. ${ }^{34}$ Though it is possible there is a critical "minimum concentration" required to achieve 17-OHPC efficacy, there are currently insufficient data to support routine clinical use of 17-OHPC levels or individualized 17-OHPC dose adjustments, though these remain active areas of research.

\section{Clinical Use of 17-OHPC}

17-OHPC is approved for the prevention of recurrent preterm birth among women with a prior singleton spontaneous preterm birth, 20-36 weeks' gestation. 17-OHPC has been commercially available since 2011, and is recommended for use by the FDA instead of compounded drug alternatives, except when there is a specific medical need (e.g., allergy) that cannot be met by the approved drug. Recently, recognizing the somewhat arbitrary nature of the lower gestational age limit cutoff, some experts have recommend extending the use of 17-OHPC and also offering it to women with a prior spontaneous preterm birth between 16 and 20 weeks' gestation, as women with such a history have a particularly high risk of recurrent preterm birth and may also benefit, though no high-quality data are available to support this recommendation. ${ }^{11,35,36}$ Offering 17-OHPC women with a previous preterm birth is the consensus recommendation of the Society for Maternal-Fetal Medicine and the American Congress of Obstetricians and Gynecologists. ${ }^{37,38}$ Current dosing recommendations are $250 \mathrm{mg}$ intramuscular weekly, beginning at 
16-20 weeks' gestation and continued through 36 weeks' gestation. Some studies suggest that earlier initiation (e.g., closer to 16 weeks) may be associated with improved outcomes, though this hypothesis has not been directly tested. ${ }^{39}$ Benefit can be seen if 17-OHPC is initiated as late as 28 weeks' gestation. Early discontinuation and poor compliance with weekly injections is associated with treatment failure and increased rates of recurrent preterm birth, though these analyses should be interpreted with caution due to confounding.

17-OHPC is classified by the US FDA as Pregnancy Category B (no known adverse effects). Limited longer term follow-up data do not suggest any adverse long-term effects; 194 children exposed to 17-OHPC in the NICHD Meis trial were evaluated at a mean of 48 months of age and had similar health outcomes and neurodevelopment to 84 children in the placebo group. ${ }^{40}$

No consistent adverse maternal effects to 17-OHPC have been identified; the most common side effects are local injection site reactions including bruising, swelling, and skin irritation. However, progestogens are known to alter the physiology of glucose transport into the cell and also may impact the release of insulin. ${ }^{41}$ The extent to which these physiologic changes in glucose metabolism also occur in response to 17-OHPC, and whether this is clinically meaningful (such as the diagnosis of gestational diabetes or glucose intolerance) remains controversial. Studies evaluating the relationship between 17-OHPC exposure and gestational diabetes are varied, as the incidence is highly dependent on the population studied and other risk factors (e.g., obesity and race). In a secondary analysis that included 2 primary studies and women with singleton and twin gestations randomized to 17-OHPC vs. placebo, rates of gestational diabetes not increased among women exposed to 17-OHPC compared to those women unexposed $(5.8 \%$ vs. $4.7 \%, p=0.64$ for singletons and $7.4 \%$ vs. $7.6 \%, p=0.94) .{ }^{42}$ In contrast, in 2014 Egerman and colleagues performed a retrospective study of 491 obese women (prepregnancy body mass index $\geq 30 \mathrm{~kg} / \mathrm{m}^{2}$ ) who received 17-OHPC (exposed cases) and 408 obese women who were undergoing daily uterine activity monitoring (unexposed controls), and reported a higher incidence of gestational diabetes among women exposed to 17 -OHPC $(13.8 \%$ vs. $9.6 \%, p=0.048) .{ }^{43} \mathrm{~A}$ recent report from a prospectively collected cohort of 430 primarly Hispanic women with a previous preterm birth treated with 17-OHPC found $13.4 \%$ developed gestational diabetes, significantly higher than the $8 \%$ rate of gestational diabetes in a historic cohort. ${ }^{34}$ Therefore, though neither a direct relationship nor causality between 17-OHPC has not been established, clinicians caring for women who are exposed to 17-OHPC should remain vigilant and perform early screening for gestational diabetes if there symptoms of glucose intolerance develop.

\section{Factors influencing successful treatment with 17-OHPC}

Unfortunately, not all women have successful term deliveries when treated with 17-OHPC. Identification of those individuals most likely to experience recurrent preterm birth despite 17-OHPC may aid clinical decision making with regards to intensity of prenatal care, timing of administration of antenatal corticosteroids, or enrollment in prospective research to investigate new therapeutic options. It is possible that risk factors from the prior pregnancy, or the underlying etiology behind the initial preterm birth influences the likelihood of recurrent preterm birth in the 17-OHPC treated pregnancy. Gonzalez-Quintero and colleagues evaluated 2123 women with one prior spontaneous preterm birth and classified the prior premature delivery as either due to "preterm labor"or "preterm premature rupture of membranes." They found that among this group of 17-OHPC treated women, those with a history of a prior preterm birth due to preterm labor had higher rates of recurrent spontaneous preterm birth $<37$ weeks $(29.7 \%$ vs. $22.9 \%, p=0.004),<35$ weeks $(14.0 \%$ vs. $9.1 \%, p=0.004)$, and $<32$ weeks (5.9\% vs. $3.3 \%, p=0.024) .{ }^{44}$ These findings were confirmed in a separate cohort of 1183 singletons, where delivery due to spontaneous preterm labor in the previous pregnancy was associated with recurrent preterm birth (OR $=1.66,95 \%$ CI: $1.16-2.37) .{ }^{45}$

Limited studies have investigated factors associated with recurrent preterm birth in the current gestation. Two

Table - Factors associated with variable pregnancy outcomes among women treated with 17-alpha hydroxyprogesterone caproate.

\begin{tabular}{|c|c|c|}
\hline Factor type & Characteristic & Association \\
\hline Family history & First degree relative with history of preterm delivery ${ }^{45}$ & Higher rate of recurrent preterm birth \\
\hline $\begin{array}{l}\text { Previous } \\
\quad \text { pregnancy }\end{array}$ & $\begin{array}{l}\text { Previous pregnancy delivered following spontaneous preterm } \\
\text { labor (vs. preterm premature rupture of membranes) }\end{array}$ & Higher rate of recurrent preterm birth \\
\hline history & Prior preterm birth $<34$ weeks $^{62}$ & $\begin{array}{l}\text { Improved prolongation of pregnancy compared } \\
\text { to women with later previous preterm births }\end{array}$ \\
\hline \multirow[t]{5}{*}{$\begin{array}{l}\text { Current } \\
\text { pregnancy }\end{array}$} & Maternal body mass index ${ }^{63,64}$ & $\begin{array}{l}\text { Higher rate of recurrent preterm birth with } \\
\text { higher maternal body mass index }\end{array}$ \\
\hline & Placental abruption or significant vaginal bleeding ${ }^{44,45}$ & Higher rate of recurrent preterm birth \\
\hline & Gonorrhea or chlamydia in the current pregnancy ${ }^{44}$ & \\
\hline & Male fetus ${ }^{44}$ & \\
\hline & Penultimate delivery was preterm ${ }^{44,45}$ & \\
\hline $\begin{array}{l}\text { Maternal } \\
\text { genetics }\end{array}$ & $\begin{array}{l}\text { Nitric oxide signal transduction, cell adhesion, cell } \\
\text { communication, signal transduction }^{49}\end{array}$ & $\begin{array}{l}\text { Pathway over-represented among women with } \\
\text { recurrent preterm birth on 17-OHPC }\end{array}$ \\
\hline
\end{tabular}


separate studies suggest that the presence of vaginal bleeding and a penultimate preterm birth are associated with an increased risk of recurrent preterm birth despite 17-OHPC therapy. ${ }^{46,47}$ Other clinical factors in the current pregnancy may also influence outcomes (Table). Finally, maternal and fetal genetics has also been evaluated as potentially influencing pregnancy outcomes and risk for recurrent preterm birth. This area of research, pharmacogenomics, investigates the association between certain genomic and epigenomic changes and response to 17-OHPC therapy for prematurity prevention. Though studies are small, some suggest that both maternal and fetal genetics may impact pregnancy outcomes among women treated with 17-OHPC. Differences in broad pathways including molecular signaling, cell adhesion, and receptor activity, as well as more specific genetic targets such as the progesterone receptor and nitric oxide synthase have been implicated (Table). ${ }^{48,49}$

\section{Real world efficacy and impact of 17-OHPC}

Multiple studies have evaluated the efficacy of 17-OHPC in the prevention of preterm birth. Mason et al. evaluated the effects of providing 17-OHPC to a high-risk, Medicaid population over a 5-year period, and found a reduction in deliveries $<35$ weeks $(41.7 \%$ in control group and $26.4 \%$ in $17-$ OHPC group) and in the rate of NICU admission $(45.0 \%$ in control group and $33.7 \%$ in $17-\mathrm{OHPC}$ group) when $17-\mathrm{OHPC}$ was initiated by 28 weeks' gestation. In 2012, Sibai et al. reported preterm birth rates less than 37 weeks' gestation were similar (34.4\% vs. 36.3\%) in a high-risk cohort of 5393 women receiving 17-OHPC through a home nurse administration care management program to the original NICHD Meis study. They also found no significant differences in adverse outcomes, suggesting that real world implementation in a home setting was safe and effective. ${ }^{50}$ Most recently, Nelson et al. ${ }^{34}$ published results from a prospective cohort of 430 women with prior births $<35$ weeks' gestation who received locally compounded 17-OHPC in the current pregnancy. Women treated with 17-OHPC (January 2012-March 2016) at a single center were compared to a historic cohort (19982001), and evaluated for recurrence of PTB $<35$ weeks' gestation. The study reported a PTB recurrence rate $<35$ weeks' gestation of $25 \%$, similar to the rate of $23 \%$ in the historic cohort $(p=0.45)$, and concluded that $17-\mathrm{OHPC}$ is ineffective in reducing the rate of recurrent prematurity. Moreover, the authors raised concern regarding the increase in the incidence of gestational diabetes in women treated with 17-OHPC, reporting a $13.4 \%$ incidence among women exposed to 17-OHPC compared with $8 \%$ in the historic cohort $(p=0.001)$. Unfortunately, it is difficult to discern the validity of these findings due the inherent errors in using a historic cohort for comparison.

It is difficult to evaluate the impact of 17-OHPC on rates of prematurity, as the addition of this intervention did not occur in isolation. Practice changes in obstetric care in the 2000s and early 2010s, including transvaginal cervical length screening, use of cervical cerclage, and vaginal progesterone to treat women with a shortened mid-trimester cervical length-along with 17-OHPC use-are estimated to have contributed the recent modest reductions in preterm birth in the United States. It is estimated that 17-OHPC use is directly responsible for the prevention of approximately 10,000 preterm births in the United States each year. ${ }^{51-53}$

\section{Use of 17-OHPC in other high-risk groups to prevent prematurity}

Progesterone as a tocolytic or adjunct tocolytic

Limited investigations have evaluated the efficacy of progestogens as acute tocolytics or adjuncts to acute tocolysis. One of the largest studies of progesterone as an acute tocolytic was a multi-center study in Europe. Investigators randomized 385 women at 24-33.9 weeks' gestation with singleton pregnancies and acute preterm labor within $48 \mathrm{~h}$ of starting acute tocolysis to receive either $200 \mathrm{mg}$ of vaginal progesterone or placebo. Progesterone use was not associated with reduction in the primary outcome of preterm birth prior to 37 weeks of gestation ( $R R=1.2,95 \% \mathrm{CI}$ : 0.93-1.5), nor with any of the other pre-specified obstetric or neonatal outcomes. ${ }^{54}$ Also in 2015, a meta-analysis was published and included 5 randomized controlled trials (441 singleton pregnancies) with arrested preterm labor found that women who received vaginal progesterone had improved outcomes, including significantly longer latency (mean improvement = 13.8 days), later gestational age at delivery (mean improvement $=1.3$ weeks), lower rates of recurrent preterm labor ( $24 \%$ vs. $46 \%$; $R R=0.51,95 \%$ CI: $0.31-0.84$ ), and lower rates of neonatal sepsis ( $2 \%$ vs. $7 \%$; $\mathrm{RR}=0.34,95 \%$ CI: 0.12-0.98)..$^{55}$

A second meta-analysis in 2015 evaluated the role of 17-OHPC as a maintenance tocolytic, and also found prolongation in latency between the initial episode of preterm labor and eventual delivery with progesterone supplementation compared with placebo (mean improvement $=8.4$ days), and later gestational age at delivery compared with placebo (mean improvement $=2.3$ weeks), though rates of preterm birth less than 37 and less than 34 weeks were similar between groups ( $42 \%$ vs. $51 \%$; $R R=0.78,95 \%$ CI: $0.50-1.22){ }^{56}$ Unfortunately, the trials included in both of these metaanalyses were of generally poor quality; for example, many were unblinded, limiting the conclusions that can be drawn from these data. Additional rigorous randomized controlled trials are needed to evaluate the efficacy of progestogens as maintenance tocolytics. At the current time, there is insufficient evidence to support routine use of either vaginal or intramuscular progesterone in the setting of active or arrested preterm labor.

\section{7-OHPC for prevention of preterm birth in other high-risk populations}

Given the success of 17-OHPC in prematurity prevention among women with a prior preterm birth, use of this intervention has also been evaluated in other high-risk populations, including multiple gestations and nulliparous women with a short cervix in the mid-trimester. In a large randomized controlled trial conducted by the NICHD Maternal Fetal Medicine Units Network, 691 women with twin pregnancies were randomized to receive either weekly 17OHPC injections or placebo starting at 16-20 weeks' gestation until 36 weeks' gestation or delivery. However, 17-OHPC did not decrease the rate of preterm birth $<35$ weeks' gestation 
( $R R=1.1,95 \% \mathrm{CI}: 0.9-1.3)$ or the composite neonatal adverse outcome $(\mathrm{RR}=1.1,95 \% \mathrm{CI}$ : $0.9-1.5)$ in this population. ${ }^{57}$ In an open label trial of 165 women with twin gestations evaluating twice weekly injections of $500 \mathrm{mg}$ of 17-OHPC, a higher rate of preterm birth $<32$ weeks was seen among women exposed to $17-$ OHPC ( $29 \%$ vs. $12 \%, p=0.007)$, though rates of preterm birth $<34$ and $<37$ weeks were not different between groups. ${ }^{58}$ Similar negative findings were appreciated in a randomized trial of 17-OHPC in 134 women with triplets $(\mathrm{RR}=1.0,95 \% \mathrm{CI}: 0.9-1.1) .{ }^{59}$ Studies evaluating the efficacy of 17-OHPC in the prevention of prematurity among women with a short cervical length have also been negative. ${ }^{60,61}$ The bulk of the evidence from these studies in women at high risk for preterm birth for other indications does not support supplementation with 17-OHPC at the current time.

\section{Conclusions}

Though much progress has been made, rates of recurrent preterm birth remain unacceptably high in the United States. Additional research is urgently needed to further elucidate both the underlying pathophysiology behind recurrent preterm birth despite 17-OHPC therapy and the clinical factors that influence outcomes. Additional refinements in 17-OHPC dosing regimens, consideration of adjunct therapies, and potentially evaluation of maternal and/or fetal genetics may help lower rates of recurrent preterm birth in the future.

\section{R E F E R E N C E S}

1. Russell RB, Green NS, Steiner CA, et al. Cost of hospitalization for preterm and low birth weight infants in the United States. Pediatrics. 2007;120(1):e1-9.

2. Manuck TA, Rice MM, Bailit JL, et al. Preterm neonatal morbidity and mortality by gestational age: a contemporary cohort. Am J Obstet Gynecol. 2016;215(1):103.e101-103 e114.

3. Manuck TA, Sheng X, Yoder BA, Varner MW. Correlation between initial neonatal and early childhood outcomes following preterm birth. Am J Obstet Gynecol. 2014;210(5):426. e421-429.

4. Natarajan G, Shankaran S. Short- and long-term outcomes of moderate and late preterm infants. Am J Perinatol. 2016;33(3): 305-317.

5. Bodeau-Livinec F, Marlow N, Ancel PY, Kurinczuk JJ, Costeloe K, Kaminski M. Impact of intensive care practices on short-term and long-term outcomes for extremely preterm infants: comparison between the British Isles and France. Pediatrics. 2008;122(5):e1014-1021 e1014-1021.

6. Vohr B. Long-term outcomes of moderately preterm, late preterm, and early term infants. Clin Perinatol. 2013;40(4): 739-751.

7. Soleimani F, Zaheri F, Abdi F. Long-term neurodevelopmental outcomes after preterm birth. Iran Red Crescent Med J. 2014; 16(6):e17965.

8. Mikkola K, Ritari N, Tommiska V, et al. Neurodevelopmental outcome at 5 years of age of a national cohort of extremely low birth weight infants who were born in 1996-1997. Pediatrics. 2005;116(6):1391-1400.

9. Grunau RE, Whitfield MF, Fay TB. Psychosocial and academic characteristics of extremely low birth weight ( $<$ or $=800 \mathrm{~g}$ ) adolescents who are free of major impairment compared with term-born control subjects. Pediatrics. 2004;114(6):e725-732.
10. Gotsch F, Gotsch F, Romero R, et al. The preterm parturition syndrome and its implications for understanding the biology, risk assessment, diagnosis, treatment and prevention of preterm birth. J Matern Fetal Neonatal Med. 2009;22(suppl 2):5-23.

11. Kramer MS, Papageorghiou A, Culhane J, et al. Challenges in defining and classifying the preterm birth syndrome. Am J Obstet Gynecol. 2012;206(2):108-112.

12. Keirse MJ. Progestogen administration in pregnancy may prevent preterm delivery. Br J Obstet Gynaecol. 1990;97(2): 149-154.

13. Meis PJ, Klebanoff M, Thom E, et al. Prevention of recurrent preterm delivery by 17 alpha-hydroxyprogesterone caproate. N Engl J Med. 2003;348(24):2379-2385.

14. Niinimaki M, Ruokonen A, Tapanainen JS, Jarvela IY. Effect of mifepristone on the corpus luteum in early pregnancy. Ultrasound Obstet Gynecol. 2009;34(4):448-453.

15. Sfakianaki AK, Norwitz ER. Mechanisms of progesterone action in inhibiting prematurity. J Matern Fetal Neonatal Med. 2006;19(12):763-772.

16. Mendelson CR. Minireview: fetal-maternal hormonal signaling in pregnancy and labor. Mol Endocrinol. 2009;23(7):947-954.

17. Garfield RE, Baulieu EE. The antiprogesterone steroid RU 486: a short pharmacological and clinical review, with emphasis on the interruption of pregnancy. Baillieres Clin Endocrinol Metab. 1987;1(1):207-221.

18. Haluska GJ, Wells TR, Hirst JJ, Brenner RM, Sadowsky DW, Novy MJ. Progesterone receptor localization and isoforms in myometrium, decidua, and fetal membranes from rhesus macaques: evidence for functional progesterone withdrawal at parturition. J Soc Gynecol Investig. 2002;9(3):125-136.

19. Oh SY, Kim CJ, Park I, et al. Progesterone receptor isoform (A/B) ratio of human fetal membranes increases during term parturition. Am J Obstet Gynecol. 2005;193(3 Pt 2):1156-1160.

20. Shynlova O, Tsui P, Dorogin A, Lye SJ. Monocyte chemoattractant protein-1 (CCL-2) integrates mechanical and endocrine signals that mediate term and preterm labor. J Immunol. 2008;181(2):1470-1479.

21. Haddad R, Tromp G, Kuivaniemi H, et al. Human spontaneous labor without histologic chorioamnionitis is characterized by an acute inflammation gene expression signature. Am J Obstet Gynecol. 2006;195(2):394.e324-391.

22. Garcia-Ruiz G, Flores-Espinosa P, Preciado-Martinez E, et al. In vitro progesterone modulation on bacterial endotoxininduced production of IL-1beta, TNFalpha, IL-6, IL-8, IL-10, MIP-1 alpha, and MMP-9 in pre-labor human term placenta. Reprod Biol Endocrinol. 2015;13:115.

23. Furcron AE, Romero R, Plazyo O, et al. Vaginal progesterone, but not 17alpha-hydroxyprogesterone caproate, has antiinflammatory effects at the murine maternal-fetal interface. Am J Obstet Gynecol. 2015;213(6):846.e819-e841.

24. Nold C, Maubert M, Anton L, Yellon S, Elovitz MA. Prevention of preterm birth by progestational agents: what are the molecular mechanisms? Am J Obstet Gynecol. 2013;208(3):223. e221-227.

25. Elovitz MA, Mrinalini C. The use of progestational agents for preterm birth: lessons from a mouse model. Am J Obstet Gynecol. 2006;195(4):1004-1010.

26. Florey K. (ed.) Hydroxyprogesterone caproate. Analytic Profiles of Drug Substances. vol 4. New York, NY: Academic Press; 1975.

27. Zhao Y, Bettinger J, Caritis S, Venkataramanan R. Stability of hydroxyprogesterone caproate alone and in a compounded pharmaceutical product. Am J Health Syst Pharm. 2014;71(13): 1120-1127.

28. Caritis SN, Sharma S, Venkataramanan R, et al. Pharmacokinetics of 17-hydroxyprogesterone caproate in multifetal gestation. Am J Obstet Gynecol. 2011;205(1):40.e41-48.

29. Caritis SN, Sharma S, Venkataramanan R, et al. Pharmacology and placental transport of 17-hydroxyprogesterone 
caproate in singleton gestation. Am J Obstet Gynecol. 2012;207(5): 398.e391-398.

30. Vyhlidal CA, Pearce RE, Gaedigk R, et al. Variability in expression of CYP3A5 in human fetal liver. Drug Metab Dispos. 2015;43(8):1286-1293.

31. Sharma S, Caritis S, Hankins G, et al. Population pharmacokinetics of 17alpha-hydroxyprogesterone caproate in singleton gestation. Br J Clin Pharmacol. 2016;82(4):1084-1093.

32. Kuehl P, Zhang J, Lin Y, et al. Sequence diversity in CYP3A promoters and characterization of the genetic basis of polymorphic CYP3A5 expression. Nat Genet. 2001;27(4):383-391.

33. Caritis SN, Venkataramanan R, Thom E, et al. Relationship between 17-alpha hydroxyprogesterone caproate concentration and spontaneous preterm birth. Am J Obstet Gynecol. 2014;210(2):128.e121-126.

34. Nelson DB, McIntire DD, McDonald J, Gard J, Turrichi P, Leveno KJ. 17-alpha hydroxyprogesterone caproate did not reduce the rate of recurrent preterm birth in a prospective cohort study. Am J Obstet Gynecol. 2017.

35. Iams JD, Berghella V. Care for women with prior preterm birth. Am J Obstet Gynecol. 2010;203(2):89-100.

36. Goldenberg RL, Mayberry SK, Copper RL, Dubard MB, Hauth JC. Pregnancy outcome following a second-trimester loss. Obstet Gynecol. 1993;81(3):444-446.

37. Committee on Practice Bulletins-Obstetrics TACoO, Gynecologists. Practice bulletin no. 130: prediction and prevention of preterm birth. Obstet Gynecol. 2012;120(4):964-973.

38. Society for Maternal-Fetal Medicine Publications Committee waoVB. Progesterone and preterm birth prevention: translating clinical trials data into clinical practice. Am J Obstet Gynecol. 2012;206(5):376-386.

39. Markham KB, Walker H, Lynch CD, Iams JD. Preterm birth rates in a prematurity prevention clinic after adoption of progestin prophylaxis. Obstet Gynecol. 2014;123(1):34-39.

40. Northen AT, Norman GS, Anderson K, et al. Follow-up of children exposed in utero to 17 alpha-hydroxyprogesterone caproate compared with placebo. Obstet Gynecol. 2007;110(4): 865-872.

41. Branisteanu DD, Mathieu C. Progesterone in gestational diabetes mellitus: guilty or not guilty? Trends Endocrinol Metab. 2003;14(2):54-56.

42. Gyamfi C, Horton AL, Momirova V, et al. The effect of 17-alpha hydroxyprogesterone caproate on the risk of gestational diabetes in singleton or twin pregnancies. Am J Obstet Gynecol. 2009;201(4):392.e391-395.

43. Egerman R, Ramsey R, Istwan $N$, Rhea D, Stanziano G. Maternal characteristics influencing the development of gestational diabetes in obese women receiving 17-alpha-hydroxyprogesterone caproate. J Obes. 2014;2014:563243.

44. Gonzalez-Quintero VH, Cordova YC, Istwan NB, et al. Influence of gestational age and reason for prior preterm birth on rates of recurrent preterm delivery. Am J Obstet Gynecol. 2011;205(3):275.e271-275.

45. Coleman S, Wallace L, Alexander J, Istwan N. Recurrent preterm birth in women treated with 17 alpha-hydroxyprogesterone caproate: the contribution of risk factors in the penultimate pregnancy. J Matern Fetal Neonatal Med. 2012;25(7): 1034-1038.

46. Manuck TA, Stoddard GJ, Fry RC, Esplin MS, Varner MW. Nonresponse to 17-alpha hydroxyprogesterone caproate for recurrent spontaneous preterm birth prevention: clinical prediction and generation of a risk scoring system. Am J Obstet Gynecol. 2016;215(5):622.e621-622.e628.

47. Manuck TA, Esplin MS, Biggio J, et al. Predictors of response to 17-alpha hydroxyprogesterone caproate for prevention of recurrent spontaneous preterm birth. Am J Obstet Gynecol. 2016;214(3):376.e371-378.

48. Manuck TA. Pharmacogenomics of preterm birth prevention and treatment. BJOG. 2016;123(3):368-375.

49. Manuck TA, Watkins WS, Moore B, et al. Pharmacogenomics of 17-alpha hydroxyprogesterone caproate for recurrent preterm birth prevention. Am J Obstet Gynecol. 2014;210(4):321. e321.

50. Sibai BM, Istwan NB, Palmer B, Stanziano GJ. Pregnancy outcomes of women receiving compounded 17 alpha-hydroxyprogesterone caproate for prophylactic prevention of preterm birth 2004 to 2011. Am J Perinatol. 2012;29(8):635-642.

51. Schoen CN, Tabbah S, Iams JD, Caughey AB, Berghella V. Why the United States preterm birth rate is declining. Am J Obstet Gynecol. 2015;213(2):175-180.

52. Chang HH, Larson J, Blencowe $\mathrm{H}$, et al. Preventing preterm births: analysis of trends and potential reductions with interventions in 39 countries with very high human development index. Lancet. 2013;381(9862):223-234.

53. Henderson ZT, Power ML, Berghella V, Lackritz EM, Schulkin J, Attitudes and practices regarding use of progesterone to prevent preterm births. Am J Perinatol. 2009;26(7):529-536.

54. Martinez de Tejada B, Karolinski A, Ocampo MC, et al, Prevention of preterm delivery with vaginal progesterone in women with preterm labour (4P): randomised double-blind placebo-controlled trial. BJOG. 2015;122(1):80-91.

55. Suhag A, Saccone G, Berghella V. Vaginal progesterone for maintenance tocolysis: a systematic review and metaanalysis of randomized trials. Am J Obstet Gynecol. 2015;213(4):479-487.

56. Saccone G, Suhag A, Berghella V. 17-alpha-hydroxyprogesterone caproate for maintenance tocolysis: a systematic review and metaanalysis of randomized trials. Am J Obstet Gynecol. 2015;213(1):16-22.

57. Rouse DJ, Caritis SN, Peaceman AM, et al. A trial of 17 alphahydroxyprogesterone caproate to prevent prematurity in twins. N Engl J Med. 2007;357(5):454-461.

58. Senat MV, Porcher R, Winer N, et al. Prevention of preterm delivery by 17 alpha-hydroxyprogesterone caproate in asymptomatic twin pregnancies with a short cervix: a randomized controlled trial. Am J Obstet Gynecol. 2013;208(3): 194.e1-8.

59. Caritis SN, Rouse DJ, Peaceman AM, et al. Prevention of preterm birth in triplets using 17 alpha-hydroxyprogesterone caproate: a randomized controlled trial. Obstet Gynecol. 2009;113(2 Pt 1):285-292.

60. Grobman WA, Thom EA, Spong CY, et al. 17 alpha-hydroxyprogesterone caproate to prevent prematurity in nulliparas with cervical length less than $30 \mathrm{~mm}$. Am J Obstet Gynecol. 2012;207(5):390.e391-398.

61. Winer N, Bretelle F, Senat MV, et al. 17 alpha-hydroxyprogesterone caproate does not prolong pregnancy or reduce the rate of preterm birth in women at high risk for preterm delivery and a short cervix: a randomized controlled trial. Am J Obstet Gynecol. 2015;212(4):485.e410-e481.

62. Spong CY, Meis PJ, Thom EA, et al. Progesterone for prevention of recurrent preterm birth: impact of gestational age at previous delivery. Am J Obstet Gynecol. 2005;193(3 Pt 2): 1127-1131.

63. Heyborne KD, Allshouse AA, Carey JC. Does 17-alpha hydroxyprogesterone caproate prevent recurrent preterm birth in obese women? Am J Obstet Gynecol. 2015;213(6):844.e841-846.

64. Co AL, Walker HC, Hade EM, Iams JD. Relation of body mass index to frequency of recurrent preterm birth in women treated with 17-alpha hydroxyprogesterone caproate. Am J Obstet Gynecol. 2015;213(2):233.e231-235. 